\title{
MÉTODOS DE IMPLANTAÇÃO DE Brachiaria sp. EM CONSÓRCIO COM MILHO VERDE
}

\author{
DEPLOYMENT METHODS OF Brachiaria sp. IN CONSORTIUM WITH GREEN \\ CORN
}

\section{João Paulo Silva SOUSA ${ }^{1}$; Luiz Fernando Ganassali de OLIVEIRA JR. ${ }^{2}$; Jailson Lara FAGUNDES ${ }^{3}$; Thiago da Silva LIMA ${ }^{4}$}

1. Professor de regime parcial, Departamento de Engenharia Agronômica, Faculdade do Nordeste da Bahia - FANEB, Coronel João Sá, BA, Brasil; jotape900@gmail.com; 2. Professor Adjunto, Centro de Ciências Agrárias Aplicadas, Departamento de Engenharia Agronômica, Universidade Federal de Sergipe, São Cristóvão, SE, Brasil; 3. Professor Adjunto, Centro de Ciências Agrárias Aplicadas, Departamento de Zootecnia, Universidade Federal de Sergipe, São Cristóvão, SE, Brasil; 4. Engenheiro Agrônomo, Centro de Ciências Agrárias Aplicadas, Departamento de Engenharia Agronômica, Universidade Federal de Sergipe, São Cristóvão, SE, Brasil;

RESUMO: O objetivo deste trabalho foi avaliar diferentes métodos de implantação de Brachiaria em consorcio com milho verde (Zea mays). O delineamento experimental foi em blocos ao acaso, que correspondeu respectivamente, ao plantio do milho com duas culturas consorciadas (Brachiaria decumbens cv. Basilisk e Brachiaria brizantha cv. Marandu), três métodos de semeadura da cultura consorciada (semeada simultaneamente com o milho, semeada com defasagem de 20 dias após o milho e cultivada simultaneamente com o milho utilizando-se de uma subdosagem de $0,5 \mathrm{~kg}$ $\mathrm{ha}^{-1}$ do ingrediente ativo ou $1 / 3$ da dosagem recomendada de herbicida para controle das plantas invasoras e das culturas consorciadas) e um tratamento adicional referente ao cultivo do milho no sistema tradicional (testemunha), em blocos ao acaso com quatro repetições. Foram analisadas as características morfogênicas e agronômicas do milho verde e de matéria seca de todo o sistema. Não foi verificado diferença $(\mathrm{p}>0,05)$ entre os tratamentos para as variáveis analisadas, com exceção da variável produção de massa seca, onde o consorcio milho com $B$. decumbens $c v$. Basilisk aplicando subdosagem de herbicida aos 20 dias de emergência os resultados mais equilibrados no sistema.

PALAVRAS-CHAVE: Brachiaria brizantha $c v$. Marandu. Brachiaria decumbens $c v$. Basilisk. Integração lavoura-pecuária. Zea mays

\section{INTRODUÇÃO}

A integração lavoura-pecuária (ILP) visa diversificar culturas favorecendo a rotação; melhorar as condições físicas do solo com pastagem nas áreas de lavoura; recuperar a fertilidade do solo com a lavoura em áreas de pastagens degradadas; aumentar a eficiência de utilização de fertilizantes e corretivos; preservar o ambiente; manejar de forma integrada as pragas, doenças e plantas daninhas; e produzir forragem para cobertura e manutenção do solo na estação seca do ano (GIMENES et al., 2009). Portanto, a ILP tem como objetivo implementar melhorias na produção vegetal e no solo, tornando possível prorrogar o tempo de uso dos campos produtivos (RAO et al., 2003).

As pastagens brasileiras, base alimentar do gado do País, vem a muitos anos sofrendo processos de degradação causados pelo mau uso do solo e deficiências de nutrientes. Esses fatores têm inviabilizado a pecuária bovina em algumas regiões (PIRES et al., 2002; MARTINS e GUILHOTO, 2001).

A intensidade e técnica da semeadura tem sido objeto de pesquisa na ILP, para obtenção de alta produtividade e sustentabilidade (PORTES et al., 2000). Em vários trabalhos, como o de NICOLOSO et al. (2006), testou-se o milho em espaçamento de $0,70 \mathrm{~m} \quad(55.000 \quad$ plantas/ha $)$ consorciado com aveia preta (Avena strigosa Schreb.) e azevém (Lolium multiflorum Lam.). PARIZ et al. (2011), que utilizaram milho com espaçamento de 0,90m com as Brachiaria brizantha cv. 'Marandu', Brachiaria decumbens, Brachiaria ruziziensis e Brachiaria híbrido cv. 'Mulato II', plantadas a lanço e na entrelinha do milho, buscaram um consórcio de boa produção de grãos e alto rendimento de matéria seca.

No processo de integração lavoura $x$ pecuária espera-se a competição entre as plantas, partindo dessa premissa veem a preocupação e a importância de se estudar os manejos possíveis para reduzir ao máximo a competição e otimizar a produção, como a utilização de subdosagem de herbicida ou plantio atrasado das Brachiarias, a fim de buscar um equilíbrio tanto na produção agrícola como da pastagem.

No processo de integração lavoura $\mathrm{x}$ pecuária espera-se a competição entre as plantas, partindo dessa premissa veem a preocupação e a importância de se estudar os manejos possíveis para reduzir ao máximo a competição e otimizar a 
produção, como a utilização de subdosagem de herbicida ou plantio atrasado das Brachiarias, a fim de buscar um equilíbrio tanto na produção agrícola como da pastagem.

No Brasil o milho verde tem importância em virtude das diversas aplicações e usos, sobretudo nas festividades dos santos juninos e o grande consumo de suas iguarias como pamonha, curau e a canjica. A importância de experimentos com milho verde, além da questão de ser um alimento de grande valor, pode trazer benefícios com a colheita antecipada e da possibilidade da área ser utilizada para a produção animal. Com a colheita da espiga (com a planta ainda verde) o restante pode ser utilizada para alimentação animal ou cobertura do solo. Nesse sentido, objetivou-se avaliar o manejo de semeadura e espécies forrageiras no sistema integração lavoura-pecuária envolvendo milho, Brachiaria decumbens cv. Basilisk e Brachiaria brizantha cv. 'Marandu', visando a produção de milho verde e estabelecimento de pasto.

\section{MATERIAL E MÉTODOS}

O estudo foi realizado no Campus Rural da Universidade Federal de Sergipe (latitude $11^{\circ} 00^{\prime} \mathrm{S}$ e longitude $37^{\circ} 12^{\prime} \mathrm{W}$ ), sendo o solo classificado como Argissolo. Antes da semeadura do milho, foi realizado análise do solo na camada de 0 a $0,20 \mathrm{~m}$ da área experimental. Os valores encontrados foram:

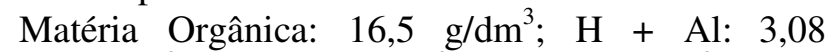
$\mathrm{cmol}_{\mathrm{c}} / \mathrm{dm}^{3}, \mathrm{~K}: 44,2 \mathrm{mg} / \mathrm{dm}^{3}$; P: 3,00 mg/dm ${ }^{3}$; Soma de bases trocáveis de $2,71 \mathrm{cmol}_{\mathrm{c}} / \mathrm{dm}^{3}$, Capacidade de troca catiônica (CTC) de $5,79 \mathrm{cmol}_{\mathrm{c}} / \mathrm{dm}^{3}$, Saturação por base (V) de 46,8\%, pH 5,09 e $\mathrm{Al}^{+3} 0,52$ $\mathrm{cmol}_{\mathrm{c}} / \mathrm{dm}^{3}$.

O delineamento experimental utilizado foi o de blocos casualizados com quatro repetições. O experimento foi constituído dos seguintes tratamentos: MS: semeadura do milho solteiro (DKB 615) (Testemunha); MBD: semeadura de milho simultaneamente com a semeadura da Brachiaria decumbens cv. Basilisk na entrelinha; MBDD: semeadura do milho com semeadura defasada de 20 dias para semeadura da Brachiaria decumbens cv. Basilisk na entrelinha do milho; MBDS: semeadura do milho simultaneamente com a semeadura da Brachiaria decumbens cv. Basilisk na entrelinha utilizando-se de uma subdosagem de herbicida (atrazina) $0,5 \mathrm{~kg}$ do ingrediente ativo $\mathrm{ha}^{-1}$ após 20 dias de emergência da Brachiaria decumbens cv. Basilisk; MBB: semeadura do milho simultaneamente com a semeadura da Brachiaria brizantha $c v$. Marandu na entrelinha; MBBD: semeadura do milho com semeadura defasada de 20 dias para semeadura da Brachiaria brizantha $c v$. Marandu na entrelinha do milho; MBBS: plantio de milho simultaneamente com a semeadura da Brachiaria brizantha $c v$. Marandu na entrelinha utilizando-se de uma subdosagem de herbicida (atrazina) $0,5 \mathrm{~kg}$ do ingrediente ativo ha ${ }^{-1}$ após 20 dias de emergência da Brachiaria brizantha $c v$. Marandu;

As unidades experimentais foram formadas por 7 fileiras de $5,00 \mathrm{~m}$ de comprimento cada. $\mathrm{O}$ espaçamento utilizado foi de $0,8 \mathrm{~m}$ x $0,2 \mathrm{~m}$ no milho com estande de 62,5 mil plantas/ha. As braquiárias foram semeadas na entrelinha do milho na densidade de $5 \mathrm{~kg} \mathrm{ha}^{-1}$ de sementes puras viáveis, no tempo requerido em cada tratamento (plantada ao mesmo tempo em que o milho ou 20 dias após a emergência do milho).

Foram realizados tratos culturais 30 dias antes do plantio, consistindo de aração e gradagem, além de calagem na proporção de $1 \mathrm{t} / \mathrm{ha} \mathrm{com}$ calcário dolomítico (incorporado) e 400kg de Super Fosfato Simples $+50 \mathrm{~kg} \mathrm{Kcl}$, segundo recomendação calculada. A semeadura do milho foi feita manualmente, utilizando três sementes por cova de $0,02 \mathrm{~m}$ de profundidade. Após? 20 dias da semeadura efetuou-se adubação de cobertura com $60 \mathrm{~kg}$ de uréia ( $45 \%$ de $\mathrm{N}$ ) e $60 \mathrm{~kg}$ de $\mathrm{KCl}(58 \%$ de $\left.\mathrm{K}_{2} \mathrm{O}\right) \mathrm{ha}^{-1}$, uma aplicação de $0,5 \mathrm{~kg} \mathrm{ha}^{-1}$ de herbicida em subdosagem de ingrediente ativo atrazina nos tratamentos com $B$. decumbens e $B$. brizantha nos tratamentos MBDS e MBBS, e a semeadura atrasada das $B$. decumbens e $B$. brizantha nos tratamentos MBDD e MBBD.

Após 25 dias de semeadura do milho foi realizado um desbaste deixando uma planta de milho/cova. O genótipo de milho utilizado foi um híbrido simples DKB 615 de ciclo superprecoce, o qual é indicado pelo ministério da Agricultura, Pecuária e Abastecimento para o Estado de Sergipe (CASTRO et. al, 2009).

Durante o ciclo da cultura do milho e após a colheita, foram avaliadas as variáveis: porcentagem de espigas atacadas por pragas (EP), contando-se as espigas que apresentaram danos causados por praga em relação ao total de espigas, sendo a principal praga encontrada a lagarta-do-cartucho (Spodoptera frugiperda); diâmetro da espiga (DE), medido com um paquímetro digital na porção mediana da espiga; número de fileiras de grãos por espiga (NFG), contados a partir da base da espiga dando uma volta completa; comprimento da espiga sem palha (CESP), medido com fita métrica da base até o ápice da espiga empalhada; peso sem palha (PSP) e peso de espiga com palha (PECP) ambos aferidos em balança digital; altura de planta (AP), medida do 
nível do solo até o nó da inserção do pendão; altura de inserção espiga principal (AE), medida do nível do solo até a inserção da espiga principal; número de plantas por fileira (estande), obtido pela contagem das plantas de cada parcela na época da colheita (NP); número de folhas da planta (NF); e número de plantas acamadas (NPA) sendo consideradas acamadas as plantas que foram encontradas no dia da contagem tombadas ao solo, de cada parcela.

Para avaliação da biomassa seca das plantas, foi colhida uma amostra aleatória de $1 \mathrm{~m}^{2}$ (retângulo de $1 \times 1 \mathrm{~m}$ ), por tratamento que foi colocado na base do colmo dos milhos alcançando a linha de brachiarias, sendo os cortes das plantas efetuados ao nível do solo. As amostras de biomassa colhidas foram separadas botanicamente, sendo eles milho (Zea mays), B. decumbens ou B. brizantha e de invasoras. Após a separação, as diferentes espécies foram pesadas ainda verdes e levadas para secagem em estufa a $65{ }^{\circ} \mathrm{C}$, onde permaneceram até a obtenção de massa constante. Após secagem, as amostras foram pesadas em balança analítica e, calculou-se o teor de massa seca (MS) de cada componente da forragem colhida na área de amostragem $\left(1 \mathrm{~m}^{2}\right)$.

Os resultados de todas as variáveis foram submetidos à análise de variância (teste f) e teste de média por skott-knot a $5 \%$ de probabilidade, utilizando-se para tanto o programa estatístico SAS (SAS Institute, 2002).

\section{RESULTADOS E DISCUSSÃO}

A produção de espigas de milho com palha e sem palha não apresentaram diferença entre os tratamentos $(\mathrm{P}>0,05)$ (Tabela 1), indicando que a competição foi equilibrada entre as plantas.

Tabela 1. Médias para produtividade de espigas com palha (PECP) $\left(\mathrm{kg} \mathrm{ha}^{-1}\right)$; produtividade de espigas sem palha (PESP) $\left(\mathrm{kg} \mathrm{ha}^{-1}\right)$; comprimento de espiga sem palha (CESP) $(\mathrm{cm})$; diâmetro de espiga (DE) (cm) DE; número de fileiras de grãos (NFG); e porcentagem de espiga atacada por praga (EP).

\begin{tabular}{|c|c|c|c|c|c|c|}
\hline TRATAMENTOS & PECP & PESP & CESP & $\mathrm{DE}$ & NFG & $\mathrm{EP}(\%)$ \\
\hline & \multicolumn{2}{|c|}{-------kg ha ${ }^{-1}$} & \multicolumn{2}{|c|}{----------cm--------- } & & \\
\hline MS & $14.026 \mathrm{a}$ & $11.407 \mathrm{a}$ & $17,10 \mathrm{a}$ & $4,3 \mathrm{a}$ & $14,50 \mathrm{a}$ & $2,75 \mathrm{a}$ \\
\hline MBD & $13.285 \mathrm{a}$ & $10.761 \mathrm{a}$ & $15,42 \mathrm{a}$ & $4,1 \mathrm{a}$ & $13,25 \mathrm{a}$ & $3,00 \mathrm{a}$ \\
\hline MBDD & $12.590 \mathrm{a}$ & $11.554 \mathrm{a}$ & $16,35 \mathrm{a}$ & $4,1 \mathrm{a}$ & $14,25 \mathrm{a}$ & $3,25 \mathrm{a}$ \\
\hline MBDS & $12.096 \mathrm{a}$ & $11.101 \mathrm{a}$ & $17,35 \mathrm{a}$ & $4,2 \mathrm{a}$ & $14,75 \mathrm{a}$ & $3,00 \mathrm{a}$ \\
\hline MBB & $12.375 \mathrm{a}$ & $10.905 \mathrm{a}$ & $18,30 \mathrm{a}$ & $4,1 \mathrm{a}$ & $14,75 \mathrm{a}$ & $2,00 \mathrm{a}$ \\
\hline MBBD & $13.203 \mathrm{a}$ & $11.875 \mathrm{a}$ & $18,32 \mathrm{a}$ & $4,2 \mathrm{a}$ & $15,50 \mathrm{a}$ & $3,00 \mathrm{a}$ \\
\hline MBBS & $12.714 \mathrm{a}$ & $12.070 \mathrm{a}$ & $17,00 \mathrm{a}$ & $4,4 \mathrm{a}$ & $15,25 \mathrm{a}$ & $2,50 \mathrm{a}$ \\
\hline $\mathrm{CV}(\%)$ & 15,96 & 9,38 & 10,84 & 4,44 & 8,68 & 5,76 \\
\hline
\end{tabular}

MS: semeadura do milho solteiro (DKB 615) (Testemunha); MBD: semeadura de milho simultaneamente com a semeadura da Brachiaria decumbens cv. Basilisk na entrelinha; MBDD: semeadura do milho com semeadura defasada de 20 dias para semeadura da Brachiaria decumbens cv. Basilisk na entrelinha do milho; MBDS: semeadura do milho simultaneamente com a semeadura da Brachiaria decumbens cv. Basilisk na entrelinha utilizando-se de uma subdosagem de herbicida (atrazina) $0,5 \mathrm{~kg}$ do ingrediente ativo ha $^{-1}$ após 20 dias de emergência da Brachiaria decumbens cv. Basilisk; MBB: semeadura do milho simultaneamente com a semeadura da Brachiaria brizantha $c v$. Marandu na entrelinha; MBBD: semeadura do milho com semeadura defasada de 20 dias para semeadura da Brachiaria brizantha $c v$. Marandu na entrelinha do milho; MBBS: plantio de milho simultaneamente com a semeadura da Brachiaria brizantha $c v$. Marandu na entrelinha utilizando-se de uma subdosagem de herbicida (atrazina) $0,5 \mathrm{~kg}$ do ingrediente ativo ha ${ }^{-1}$ após 20 dias de emergência da Brachiaria brizantha $c v$. Marandu; Médias na coluna, seguidas da mesma letra, não diferem a $5 \%$ de probabilidade.

Jakelaitis et al. (2004) constataram em experimentos com milho consorciado com $B$. brizantha que a presença da forrageira não afetou a cultura do milho, sendo o milho ótimo competidor nesse tipo de consórcio. Da mesma forma, a utilização de atrazina no consórcio entre milho e gramíneas forrageiras tem sido uma prática recomendada no controle de plantas forrageiras sobre a cultura e de plantas invasoras (JAKELAITIS et al., 2004). Os valores de produção de espiga estão condizentes com outros trabalhos visando a produção de milho verde, como os apresentados por ALBUQUERQUE et al. (2008) e PEREIRA et al. (2009). 
Não se observou diferença $(\mathrm{P}>0,05)$ para o comprimento de espiga sem palha, diâmetro de espiga e número de fileiras de grãos por espiga (Tabela 1), reforçando que possivelmente não houve competição entre espécies forrageiras e o milho. Esse resultado foi em função da ocupação controlada das espécies de Brachiaria na entrelinha do milho, num espaçamento adequado, minimizando a competição por nutrientes, água e luminosidade. O comprimento e diâmetro da espiga sem palha são atributos importantes, sendo consideradas comercializáveis as espigas que apresentam comprimento maior que $15 \mathrm{~cm}$ e diâmetro maior que $3 \mathrm{~cm}$ (PAIVA JÚNIOR et al., 2001).

Não se observou diferença entre os tratamentos $(\mathrm{P}>0,05)$ para os resultados de espigas atacadas por praga. Durante o experimento não foram detectada presença em níveis de dano de insetos praga.

A altura de planta do milho não apresentou diferença $(\mathrm{P}>0,05)$ entre os tratamentos. (Tabela 2), cuja média geral foi de $176,45 \mathrm{~cm}( \pm 3,70)$. Segundo a DEKALB®, o milho DKB 615 apresenta crescimento de 180,00 a $210,00 \mathrm{~cm}$. Tal resultado confirma os estudos realizados por Young (1981), que demonstrou redução na altura de plantas de milho quando em desenvolvimento simultâneo com plantas infestantes e forrageiras consorciadas, sendo assim, a altura de inserção de espiga também foi reduzida, mas isso não chegou a afetar a produção de grãos do milho.

Os resultados a $(\mathrm{P}>0,05)$ entre os tratamentos (Tabela 2) não apresentaram diferença para os resultados do número de plantas por parcela e o número de espigas por tratamento.

Tabela 2. Médias para altura de planta (AP), altura de inserção de espiga principal (AE), número de plantas (NP), número de espigas (NE).

\begin{tabular}{ccccc}
\hline TRATAMENTOS & AP & AE & NP & NE \\
\hline MS & $173,75 \mathrm{a}$ & $63,75 \mathrm{a}$ & $22,75 \mathrm{a}$ & $23,75 \mathrm{a}$ \\
MBD & $178,75 \mathrm{a}$ & $68,75 \mathrm{a}$ & $23,75 \mathrm{a}$ & $24,50 \mathrm{a}$ \\
MBDD & $177,50 \mathrm{a}$ & $70,00 \mathrm{a}$ & $22,75 \mathrm{a}$ & $24,50 \mathrm{a}$ \\
MBDS & $176,25 \mathrm{a}$ & $66,25 \mathrm{a}$ & $23,75 \mathrm{a}$ & $24,75 \mathrm{a}$ \\
MBB & $176,25 \mathrm{a}$ & $67,50 \mathrm{a}$ & $24,00 \mathrm{a}$ & $25,00 \mathrm{a}$ \\
MBBD & $176,25 \mathrm{a}$ & $67,50 \mathrm{a}$ & $24,25 \mathrm{a}$ & $25,50 \mathrm{a}$ \\
MBBS & $186,25 \mathrm{a}$ & $73,75 \mathrm{a}$ & $25,00 \mathrm{a}$ & $25,75 \mathrm{a}$ \\
\hline CV $(\%)$ & 4,89 & 10,24 & 5,34 & 6,88
\end{tabular}

MS: semeadura do milho solteiro (DKB 615) (Testemunha); MBD: semeadura de milho simultaneamente com a semeadura da Brachiaria decumbens cv. Basilisk na entrelinha; MBDD: semeadura do milho com semeadura defasada de 20 dias para semeadura da Brachiaria decumbens cv. Basilisk na entrelinha do milho; MBDS: semeadura do milho simultaneamente com a semeadura da Brachiaria decumbens $\mathrm{cv}$. Basilisk na entrelinha utilizando-se de uma subdosagem de herbicida (atrazina) $0,5 \mathrm{~kg}$ do ingrediente ativo ha $^{-1}$ após 20 dias de emergência da Brachiaria decumbens cv. Basilisk; MBB: semeadura do milho simultaneamente com a semeadura da Brachiaria brizantha $c v$. Marandu na entrelinha; MBBD: semeadura do milho com semeadura defasada de 20 dias para semeadura da Brachiaria brizantha $c v$. Marandu na entrelinha do milho; MBBS: plantio de milho simultaneamente com a semeadura da Brachiaria brizantha $c v$. Marandu na entrelinha utilizando-se de uma subdosagem de herbicida (atrazina) $0,5 \mathrm{~kg}$ do ingrediente ativo ha ${ }^{-1}$ após 20 dias de emergência da Brachiaria brizantha cv. Marandu; Médias na coluna, seguidas da mesma letra, não diferem a 5\% de probabilidade.

O desenvolvimento cespitoso da $B$. brizantha e o decumbente da $B$. decumbens, não impuseram nenhuma condição diferenciada ao manejo, visto que o milho manteve seu desenvolvimento homogêneo. Segundo Fancelli e Dourado Neto (2000), qualquer estresse que cultura agrícola seja submetida após o florescimento, de ordem nutricional ou competição exercida por planta forrageira podem diminuir a produção de grãos. Os dados demonstram que os tratamentos mantiveram o consórcio equilibrado, pois foi observado que no geral, os métodos de implantação propiciaram o franco desenvolvimento de ambas as espécies consorciadas, estabelecendo limites a competição e sendo possível obter uma produção economicamente viável e de caráter sustentável no prisma da conservação e uso de recursos (água e solo).

A produção de biomassa seca de milho e das braquiárias apresentaram diferença $(\mathrm{P}>0,05)$ entre os tratamentos (Tabela 3), sendo possível inferir sobre o potencial dos consórcios em questão. 
Tabela 3. Médias para produção de massa seca de milho (planta inteira), Brachiaria, das plantas invasoras e massa seca total $(\mathrm{kg} / \mathrm{ha})$ nos diferentes tratamentos implantados.

\begin{tabular}{|c|c|c|c|c|}
\hline \multirow{2}{*}{ Tratamentos } & \multicolumn{4}{|c|}{ Produção de Massa Seca } \\
\hline & Milho & Brachiaria & Invasoras & Total \\
\hline & & 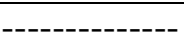 & & \\
\hline MS & $7.544 \mathrm{a}$ & - & $300 \mathrm{~b}$ & $7.844 \mathrm{~b}$ \\
\hline MBD & $3.980 \mathrm{~b}$ & $3.338 \mathrm{~b}$ & $600 \mathrm{a}$ & $7.918 \mathrm{~b}$ \\
\hline MBDD & $5.373 \mathrm{~b}$ & $2.945 \mathrm{~b}$ & $800 \mathrm{a}$ & $9.118 \mathrm{a}$ \\
\hline MBDS & $5.106 \mathrm{~b}$ & $6.057 \mathrm{a}$ & $550 \mathrm{~b}$ & $11.713 \mathrm{a}$ \\
\hline MBB & $4.500 \mathrm{~b}$ & $4.470 \mathrm{~b}$ & $600 \mathrm{a}$ & $9.570 \mathrm{a}$ \\
\hline MBBD & $5.000 \mathrm{~b}$ & $1.000 \mathrm{c}$ & $1.200 \mathrm{a}$ & $7.200 \mathrm{~b}$ \\
\hline MBBS & $4.200 \mathrm{~b}$ & $3.086 \mathrm{~b}$ & $600 \mathrm{a}$ & $7.886 \mathrm{~b}$ \\
\hline $\mathrm{CV}(\%)$ & 25,28 & 28,80 & 17,95 & 39,43 \\
\hline
\end{tabular}

MS: semeadura do milho solteiro (DKB 615) (Testemunha); MBD: semeadura de milho simultaneamente com a semeadura da Brachiaria decumbens cv. Basilisk na entrelinha; MBDD: semeadura do milho com semeadura defasada de 20 dias para semeadura da Brachiaria decumbens cv. Basilisk na entrelinha do milho; MBDS: semeadura do milho simultaneamente com a semeadura da Brachiaria decumbens cv. Basilisk na entrelinha utilizando-se de uma subdosagem de herbicida (atrazina) $0,5 \mathrm{~kg}$ do ingrediente ativo ha $^{-1}$ após 20 dias de emergência da Brachiaria decumbens cv. Basilisk; MBB: semeadura do milho simultaneamente com a semeadura da Brachiaria brizantha $c v$. Marandu na entrelinha; MBBD: semeadura do milho com semeadura defasada de 20 dias para semeadura da Brachiaria brizantha $\mathrm{cv}$. Marandu na entrelinha do milho; MBBS: plantio de milho simultaneamente com a semeadura da Brachiaria brizantha $c v$. Marandu na entrelinha utilizando-se de uma subdosagem de herbicida (atrazina) $0,5 \mathrm{~kg}$ do ingrediente ativo ha ${ }^{-1}$ após 20 dias de emergência da Brachiaria brizantha $c v$. Marandu; Médias na coluna, seguidas da mesma letra, não diferem a $5 \%$ de probabilidade.

A espécie B. decumbens em MBDS alcançou uma produtividade de $6.057 \mathrm{~kg} / \mathrm{ha}$, bem acima dos números alcançados nos arranjos de semeadura com B. brizantha. Esses resultados são contrastantes, pois segundo Silva et al. (2008), em um sistema de integração lavoura-pecuária a $B$. brizantha não apresentou diferença significativa consorciada com o milho, já a $B$. decumbens consorciada com milho apresentou menor produtividade de matéria seca. $\mathrm{O}$ arranjo de semeadura de MBDS revela uma nova concepção sobre os consórcios de milho com $B$. decumbens. Pode-se inferir que em MBDS as plantas não foram prejudicadas pelo desenvolvimento do milho, MBBD foi o tratamento de menor produtividade de biomassa seca de $B$. brizantha com $1.000 \mathrm{~kg} / \mathrm{ha}$, dessa maneira, propiciou o crescimento de invasores que atingiram $1,200 \mathrm{Kg} / \mathrm{ha}$. Boa parte dessas invasoras não tinham valor nutricional para alimentação animal. Souza Neto et al. (2002) também constataram prejuízo no rendimento forrageiro de $B$. brizantha nas épocas de semeadura mais tardias.

Verificou-se que a produção de massa seca (MS) do milho foi influenciada $(\mathrm{p}<0,05)$ nos tratamentos testados (Tabela 3). Pois, notou-se que a inclusão da semeadura de forrageiras associadas ao cultivo do milho diminui a sua produção de (MS), entretanto constatou-se que a mesma não comprometeu a produção das espigas de milho (Tabela 1). Pode-se inferir que a semeadura das espécies de Brachiaria de forma associada com o milho permite que o solo tenha um bom material de cobertura, e formação de bom pasto para a alimentação animal, com destaque para o MBDS. Dentre os métodos de implantação, o milho mais $B$. decumbens, aplicando subdosagem de herbicida aos 20 dias de emergência (MBDS), proporcionou os melhores resultados em produção de MS demonstrando que a $B$. decumbens cultivada neste método propicia bons resultados produtivos.

A produção de biomassa seca total apresentou diferença $(\mathrm{p}<0,05)$ entre os tratamentos. Sendo MBDS com $11.713 \mathrm{~kg} / \mathrm{ha}$ o de maior rendimento e estatisticamente igual ao MBDD e MBB. Esses resultados levam a concluir que o arranjo de semeadura obteve êxito produtivo e as condições de desenvolvimento da $B$. decumbens foram notadamente superiores em relação a $B$. brizantha nos manejos de semeadura propostos nesse trabalho. Isso demonstra que o uso de uma subdosagem de herbicida assegurou boa produção de espiga de milho, sem comprometer a sua produção de massa seca, possibilitando uma boa produção de $B$. decumbens, uma boa cobertura do solo e um produto para alimentação animal.

A incidência de plantas invasoras apresentou diferença entre os tratamentos $(\mathrm{P}<0,05)$. Os tratamentos MS e MBB, com 300 e 500 e kg/ha de MS de invasoras, respectivamente, tiveram a menor incidência, provavelmente devido ao bom desenvolvimento do milho e da $B$. brizantha que ocuparam o solo, sombreando e competindo com as plantas daninhas por espaço, nutrientes e água.

Severino et al. (2005) observaram rendimento da cultura do milho da ordem de 4.000 
$\mathrm{kg} \mathrm{ha}^{-1}$ de biomassa obtido no consórcio com $B$. decumbens e Possamai et al. (2001), cultivando milho em semeadura direta, arado de aiveca, arado de discos, grade pesada e enxada rotativa, obtiveram produtividade da ordem de $3.300 \mathrm{~kg} \mathrm{ha}^{-1}$ para o sistema de plantio direto, ambos valores inferiores aos encontrados neste trabalho.

\section{CONCLUSÕES}

Os consórcios das espécies Brachiaria decumbens $c v$. Basilisk e Brachiaria brizantha $c v$.
Marandu com milho verde são praticas viáveis e não comprometem a produção de milho verde.

Dentre os arranjos de semeadura, o milho em consórcio com B. decumbens cv. Basilisk aplicando subdosagem de herbicida aos 20 dias de emergência proporciona resultados mais equilibrados (produção de grãos e biomassa), sendo esse um ponto chave para o sucesso do sistema.

\begin{abstract}
The objective of this study was to evaluate different methods of deploying Brachiaria in consortium with corn (Zea mays). The experimental design was randomized blocks, which corresponded respectively to the planting of corn with two companion crops (Brachiaria decumbens cv. Basilisk and Brachiaria brizantha cv. Marandu), three methods of seeding intercropped crop (planted simultaneously with maize, sown with a lag of 20 days after maize and maize grown simultaneously with using a dosing of $0.5 \mathrm{~kg} \mathrm{ha}^{-1}$ of active ingredient or $1 / 3$ of the recommended dose of herbicide to control invasive plants and intercropping) and an additional treatment related to maize cultivation in the traditional system (control) in a randomized block design with four replications. Morphogenetic and agronomic characteristics of corn and dry matter of the whole system were analyzed. There was no difference $(p>0.05)$ between treatments for the analyzed variables, except the variable dry matter production where the corn consortium with B. decumbens underdosing applying herbicide at 20 days of emergency in the most balanced results system.
\end{abstract}

KEYWORDS: Brachiaria brizantha cv. Marandu. Brachiaria decumbens cv. Basilisk. Integrated croplivestock. Zea mays

\title{
REFERÊNCIAS
}

ALLEN, V. G.; BAKER, M. T., SEGARRA, E.; BROWN, C. P. Integrated irrigated crop-livestock systems in dry climates. Agronomy Journal, Madison, v. 99, n. 2, p. 346-360, 2007. Disponível em: <https://www.agronomy.org/publications/aj/articles/99/2/346>. Acesso em: 17 maio. 2012.

ALVARENGA, R. C.; COBUCCI, T.; KLUTHCOUSKI, J.; WRUCK, F. J.; CRUZ, J. C.; GONTIJO NETO, M. M. A cultura do milho na integração lavoura-pecuária. Informe Agropecuário, Belo Horizonte, v. 27, n. 233, p. 106-126, jul./ago. 2006. Disponível em: <http://www.cnpms.embrapa.br/publicacoes/publica/2006/circular/Circ_80.pdf>

ALBUQUERQUE, C. J. B.; Pinho, R. G. V.; Borges, I. D.; Filho, A. X. de S.; Fiorini, I. V. A. Desempenho de híbridos experimentais e comerciais de milho para produção de milho verde. Ciênc. agrotec., Lavras, v. 32, n. 3, p. 768-775, 2008. Disponível em: <http://www.scielo.br/pdf/cagro/v32n3/a10v32n3.pdf>

CASTRO, C. R.; CARVAlHO, H. W. L. de; CARDOSO, M. J.; PACHECO, C. A. P.; ROCHA, L. M. P.; OLIVEIRA, I. R. de; TABOSA, J. N.; RODRIGUES, C. S.; MENEZES, V. M. M. Comportamento de Cultivares de Milho no Nordeste Brasileiro: Safra 2009/2010. Disponível em: < http://ainfo.cnptia.embrapa.br/digital/bitstream/item/41089/1/3607.pdf>

EUCLIDES, V. P. B. et al. Brazilian scientific progress in pasture research during the first decade of XXI century. Revista Brasileira de Zootecnia, Viçosa, v.39, supl. especial, p.151-168, 2010. $<$ http://www.scielo.br/pdf/rbz/ v39sspe/18.pdf>

DEKALB, 2009. http://www.dekalb.com.br/produto_milho_safrinha.aspx?id=50 Acessado em 27/11/2009.

FANCELLI, A. L.; DOURADO NETO, D. Produção de milho. Guaíba: Agropec, 2000. 360p. 
GIMENES, M. J.; DAL POGETO, M. H. F. A.; PRADO E. P.; SOUZA, R. S. C. E. F. C. Integração lavourapecuária-breve revisão. Revista Trópica, v. 4, p. 52, 2009.

JAKELAITIS, A., SILVA, A. A., FERREIRA, L. R., SILVA, A. F. e FREITAS, F. C. L. MANEJO DE PLANTAS DANINHAS NO CONSÓRCIO DE MILHO COM CAPIM-BRAQUIÁRIA (Brachiaria decumbens). Planta Daninha, Viçosa-MG, v. 22, n. 4, p. 553-560, 2004. Disponível em: < http://www.scielo.br/pdf/pd/v22n4/a09v22n4.pdf>

KLUTHCOUSKI, J.; COBUCCI, T.; AIDAR, H.; OLIVEIRA, I. P.; COSTA, J. L. S.; BARCELLOS, A. O.; MAGNABOSCO, C. U. Sistema Santa Fé - Tecnologia Embrapa: integração lavoura-pecuária pelo consórcio de culturas anuais com forrageiras, em áreas de lavoura, nos sistemas direto e convencional. Embrapa Arroz e Feijão, 2000. 28p. Disponível

em:<http://www.cefetbambui.edu.br/grupos_de_estudo/gesa/download/livros/sistema_santa_fe_integracao_lav oura_pecuaria.pdf $>$

KLUTHCOUSKI, J.; YOKOYAMA, L. P. Opções de integração lavoura-pecuária. In: KLUTHCOUSKI, J. et al. Integração Lavoura-Pecuária. Santo Antonio de Goiás: Embrapa Arroz e Feijão, 2003. Cap.4, p. 131-141.

MARTINS, P. C.; GUILHOTO, J. J. Leite e derivados e a geração de emprego, renda e ICMS no contexto da economia brasileira. In: O agronegócio do leite no Brasil. (ed). ALOÍSIO TEIXEIRO GOMES, JOSÉ LUIZ BELLINI LEITE, ALZIRO VASCONCELOS CARNEIRO. Juiz de Fora: Embrapa Gado e Leite, 2001. p. 181205.

NICOLOSO, R. S.; LANZANOVA, M. E.; LOVATO T. Manejo das pastagens de inverno e potencial produtivo de sistemas de integração lavoura-pecuária no Estado do Rio Grande do Sul. Ciência Rural, Santa Maria, v. 36, n. 6, p. 1799-1805, 2006 <www.scielo.br/pdf/cr/v36n6/a20v36n6.pdf>

PAIVA JÚNIOR, M. C. de; PINHO, R. G. von; PINHO, E. V. R. von; RESENDE, S. G. de. Desempenho de cultivares para a produção de milho verde em diferentes épocas e densidades de semeadura em Lavras-MG.

Ciência e Agrotecnologia, Lavras, v. 25, n. 5, p. 1235-1247, 2001. < http://www.editora.ufla.br/_adm/upload/revista/25-5-2001_24.pdf>

PARIZ, C. M.; ANDREOTTI M.; AZENHA, M. V.; BERGAMASCHINE A. F.; MELLO L. M. M.; LIMA, R. C. Produtividade de grãos de milho e massa seca de braquiárias em consórcio no sistema de integração lavourapecuária. Ciência Rural, Santa Maria, v. 41, n. 5, p. 875-882, 2011.. <

http://www.scielo.br/pdf/cr/v41n5/a942cr2241.pdf>

PEREIRA, A. F.; MELO P. G. S.; PEREIRA, J. M.; ASSUNÇÃO A. 1; NASCIMENTO A. R.;

XIMENES P. A. Caracteres agronômicos e nutricionais de genótipos de milho doce. Biosci. J., Uberlândia, v. 25, n. 1, p. 104-112. 2009. Disponível em: < http://www.sumarios.org/sites/default/files/pdfs/27542_3651.PDF>

PIRES, A. J. V.; MAGALHÃES, A. F.; CARVALHO, G. G. P. de. Recuperação de pastagens degradadas. In: SEMANA DE CIÊNCIAS AGRÁRIAS DA UESB, 2., 2002, Itapetinga, BA. Anais... Itapetinga: UESB, 2002. p.14-26.

PORTES, T. A.; CARVALHO, S. I. C.; OLIVEIRA, I. P.; KLUTHCOUSKI, J. Análise do crescimento de uma cultivar de braquiária em cultivo solteiro e consorciado com cereais. Pesq. Agropec. Bras., v. 35, n. 7, p.13491358, 2000. Disponível em: < http://www.scielo.br/pdf/pab/v35n7/1349.pdf>

POSSAMAI, J. M.; SOUZA, C. M.; GALVÃO, J. C. C. Sistemas de preparo do solo para o cultivo do milho safrinha. Bragantia, v. 60, p. 79-82, 2001. Disponível em: < http://www.scielo.br/pdf/brag/v60n2/a03v60n2.pdf> 
RAO, S. C.; PHILLIPS, W. A.; MAYEUX, H. S.; PHATAK, S. C. Potential Grain and Forage Production of Early Maturing Pigeonpea in the Southern Great Plains. Crop Science, Madison, v. 43, n. 6, p. 2212-2217, 2003. http://dx.doi.org/10.2135/cropsci2003.2212

STATISTICAL ANALYSES SYSTEM - SAS. Disponível em: http://sasdocs.ucdavis.edu. Acesso em: 20 de abril de 2002.

SEVERINO, F. J.; CARVALHO, S. J. P.; CHRISTOFOLETI, P. J. Interferências mútuas entre a cultura do milho, espécies forrageiras e plantas daninhas em um sistema de consórcio. I- Implicações sobre a cultura do milho (Zea mays). Planta Daninha, Viçosa-MG, v. 23, n.4, p. 589-596, 2005. Disponível em:

$<$ http://www.scielo.br/scielo.php?script=sci_arttext\&pid=S0100-83582005000400005>

SILVA E. T., CUNHA J. L. X. L., MADALENA J. A. S., SILVA J. A. C., SILVA, W. T. Produção de milho (zea mays 1.) em consórcios com gramíneas forrageiras. Caatinga Mossoró, v. 21, n. 4, p.29-34, de 2008. < http://periodicos.ufersa.edu.br/revistas/index.php/sistema/article/view/830/440>

SOUZA NETO, J. M.; PEDREIRA, C. G. S.; COSTA, G. B. Estabelecimento de pastagens de Brachiaria brizantha cv. Marandu com milho como cultura acompanhante. In: REUNIÃO ANUAL DA SOCIEDADE BRASILEIRA DE ZOOTECNIA, 40., 2002, Recife. Anais... Viçosa: SBZ, 2002. CD-ROM.

YOUNG, F. L. Quackgrass (Agropyron repens) interference in corn (Zea mays) and soybeans (Glycine max). Apud Disertation Abstracts International B. Ann arbor, v. 42, n. 6, p. 2173-2174, December, 1981. 